\title{
Über die Darstellung von Cäsium aus seinem Karbonate.
}

\author{
Von
}

\author{
Edmund Graefe und Moritz Eckardt.
}

Eine der schwierigsten Aufgaben der präparativen Chemie war bislang die Darstellung von metallischem Cäsium, was auch den hohen Preis von ca. 28 Mark pro Gramm erklärlich erscheinen lälst. An Versuchen, Abscheidungsverfahren für dies Metall, das schon als das positivste ein besonderes Interesse beansprucht, hat es zwar nicht gefehlt. SeTterRere ${ }^{1}$ stellte es durch Elektrolyse eines Gemisches von 4 Teilen $\mathrm{CsCN}_{\mathrm{S}}$ und 1 Teil $\mathrm{Ba}(\mathrm{CN})_{2}$ dar, Erdmann und Menke ${ }^{2}$ isolierten es aus dem Hydroxyde, WINKLER ${ }^{3}$ versuchte es aus dem Karbonate darzustellen, erhielt aber ein negatives Resultat. Er hatte schon vorher Lithium, Natrium, Kalium und Rubidium durch Reduktion ihrer kohlensauren Salze mit Magnesium dargestellt, und zwar erhielt er die Metalle, da er mit sehr kleinen Quantitäten operierte, in Form von Metallspiegeln im Reduktionsrohre. Bei Cäsium dagegen versagte die Methode, er konnte es trotz mehrfachem Bemühen nicht abscheiden, und er gelangte zu dem Schlusse, dals BeKETow's Behauptung, die Reduzierbarkeit der Alkalimetalle wachse mit steigendem Atomgewichte, sich nicht aufrecht erhalten liefse.

Als wir das WinkLen'sche Verfahren in etwas grölserem Mafsstabe ausführten, zeigte es sich, dals diese Methode zur Darstellung von gröfseren Quantitäten der Alkalimetalle eine sehr geeignete war. Wir stellten nach ihr zunächst Kalium und Rubidium dar und verfuhren wie folgt:

Ungefähr $30 \mathrm{~g}$ eines nach der Gleichung ${ }^{1} \mathrm{R}_{2} \mathrm{CO}_{3}+3 \mathrm{Mg}=$ $2^{1} \mathrm{R}+3 \mathrm{MgO}+\mathrm{C}$ zusammengesetzten Gemisches wurden vorsichtig im

1 Ladenbura, Handwörterbuch.

2 Chem. Centralbl. (Auszug) $1899[\mathrm{I}] 17$.

${ }^{3}$ Ber. deutsch. chem. Ges. [1] 23, 51. 
Eisenrohre in einem mit Holzkohlen geheizten Verbrennungsofen erhitzt und die Hitze nach und nach bis zur hellen Rotglut gesteigert. Als Transportmittel für die Metalldämpfe diente sorgfältig getrockneter Wasserstoff, der im langsamen Strome durch das Rohr geleitet wurde. Im kälteren Teil des letzteren verdichtete sich der Dampf, und die Metalle tropften in silberhellen Kugeln in das vorgelegte Paraffinbad, das bei der Darstellung von Kalium, um Verstopfungen des Rohres zu vermeiden, zweckmälsig erwärmt wurde. Waren die angewendeten Materialien sorgfältig getrocknet, so waren die Ausbeuten fast quantitativ. Bei der heftigen Reaktion der Alkalimetalle mit Wasser war es sehr unerwünscht, dafs trotz aller Vorsichtsmalsregeln doch Spuren von Wasser in das Vorlagegefäls gelangten und dort zur Oxydation der abdestillierten Metalle Anlafs gaben. Es rührte dies von $\mathrm{Fe}_{2} \mathrm{O}_{3}$ her, das sich ungeachtet der sorgfältigsten Reinigung doch nicht ganz aus der Röhre entfernen liefs und beim Erhitzen im Wasserstoffstrome unter Wasserbildung reduziert wurde; es lärst sich das durch vorherige Reduktion des Rohres im Wasserstoffstrome vermeiden.

Wir fanden bei unserer Arbeit, dals sich, entgegengesetzt zu WinkLer's Resultaten, Rubidium leichter als Kalium reduzieren liefs. Das brachte uns auf den Gedanken, es könne ein ähnliches Verhalten auch zwischen Cäsium und Rubidium bestehen, und wir beschlossen, einen Reduktionsversuch anzustellen. Derselbe erfolgte in gleich grofsem Mafsstabe wie bei Kalium und Rubidium und in der gleichen Versuchsanordnung. Schon bei einer Temperatur, die bedeutend niedriger war als die zur Reduktion von Rubidium oder gar von Kalium notwendige, ging die Zersetzung des Karbonats glatt von statten. Die Abdestillation des Cäsiums erfolgte mit grofser Schnelligkeit, so dafs sich das Metall in Form eines silberhellen Strahles in das vorgelegte Gefäls ergols. Die Farbe des in fast quantitativer Ausbeute erhaltenen Metalls war silberweifs mit einem Stich ins Gelbe; seinen Metallglanz behielt es beim Aufbewahren unter Paraffinöl bei. An die Luft gebracht erhitzt es sich durch Oxydation, schmilzt und entzündet sich; auf Wasser geworfen schwimmt es unter starker Wasserstoffentwickelung herum und brennt sofort mit rotvioletter Flamme.

Unsere Versuche zeigten also, dals BeKETow's Behauptung, die Reduzierbarkeit der Alkalimetalle nehme mit dem Steigen der Atomgewichte za, völlig zu Recht besteht. 
Da sich auf die angegebene Weise Cäsium wie auch Rubidium mit verhältnismälsig wenig Aufwand von Kosten und Mühe, namentlich da die Ausbeuten fast quantitativ sind, in beliebig grofsen Mengen darstellen lassen - wir erhielten z. B. bei einer einzigen Operation $70 \mathrm{~g}$ Rubidium - so beabsichtigen wir, das physikalische und chemische Verhalten dieser beiden interessanten Metalle etwas eingehender, als es bis jetzt geschah, zu untersuchen und dabei auch der Frage nach ihrer Absorptionsfähigkeit für Gase näher zu treten und behalten uns vor, in nächster Zeit darüber Mitteilung zu machen.

Es drängt uns noch, auch an dieser Stelle unseren verehrten Lehrern, Herrn Geheimrat Prof Dr. Hempex und Herrn Prof. Dr. Foenster, unseren herzlichsten Dank für gütigen Rat und Unterstützung bei unserer Arbeit auszusprechen.

Dresden, Anorg.-chemisches Laboratorium der k. sächs. techn. Hochschule, 29. Juli 1899.

Bei der Redaktion eingegangen am 8. August 1899. 